\title{
Realidade Aumentada e a Cyberformação de uma Professora de Matemática: Pontos Críticos de Funções de Duas Variáveis ${ }^{1}$
}

\section{Augmented Reality and the Cybereducation of a Mathematics Teacher: Critical Points of Functions of Two Variables}

\author{
Paula Etiele Sarmento Schuster*a; Maurício Rosa ${ }^{\mathrm{a}}$

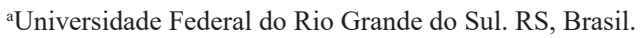 \\ *E-mail: ps.schuster@gmail.com
}

\begin{abstract}
Resumo
Essa pesquisa investiga como uma professora constitui conhecimento matemático quando está estudando pontos críticos com gráficos produzidos em Realidade Aumentada (RA). Esta é uma pesquisa qualitativa que possui seu foco no processo formativo experienciado pela professora/pesquisadora em termos de Cyberformação, pois ela é a sujeito de sua própria investigação. Assim, a autoanálise em termos metodológicos concentra-se em estudos individuais da professora/pesquisadora, em um movimento rigoroso de gravação de dados, afastamento desses e análise, compreendendo que a constituição de conhecimento se dá "Com-Holográficos", pois se refere ao ato de ser-com-Tecnologias Digitais (TD) de RA, no qual a professora/pesquisadora ao estar no contexto de RA se pluga com essa tecnologia pela materialidade que a expressa, possibilitando uma mudança de perspectiva matemática, sustentando por meio da TD expressões de aspectos matemáticos não vistos anteriormente. Logo, indicamos que a constituição do conhecimento matemático de uma professora em Cyberformação com TD de RA se dá por meio de interações com o contexto de RA, de forma indissociável e como fluxos matemáticos, pedagógicos e tecnológicos que se entrecruzam. A pesquisa contribui para a compreensão do processo de constituição do conhecimento matemático da professora e isso permite, em termos de formação, que professores entendam-se no processo para projetar/planejar suas aulas de matemática com o recurso de RA.
\end{abstract}

Palavras-chave: Educação Matemática. Formação de Professores. Autoanálise. Gráficos. Holográficos.

\begin{abstract}
This research investigates how a teacher constitutes mathematical knowledge when she is studying critical points through graphics produced in an Augmented Reality (AR) environment. The research is qualitative, whose focus is on the formative process experienced by the teacher/ researcher in terms of Cybereducation, because she is the subject of her own research. The production of data was stored through audiovisual recordings which, in this article, focus on individual studies by the teacher/researcher. Thus, we understand that the constitution of knowledge is "With-Holographics", because it refers to the act of being-with-Digital Technologies (DT) of AR, in which the teacher/researcher being in the context created by the RA connects with this technology due to the materiality it expresses. Thus, allowing a change in teacher's perspective and an alteration in her mathematical performance, supporting through DT expressions of mathematical aspects not previously seen. Therefore, this research indicates that the constitution of the mathematical knowledge of a teacher in Cybereducation with DT of AR occurs inseparably through interactions with the context and as mathematical, pedagogical and technological flows that intersect.
\end{abstract}

Keywords: Mathematics Education. Teachers' Training. Graphics. Holographics.

\section{Introdução}

Atualmente vivenciamos uma sociedade avançada tecnologicamente devido aos recursos que surgem constantemente. Segundo Vanini, Rosa, Justo e Pazuch (2013) existem indivíduos que acessam a Internet com diferentes propósitos (redes sociais, trocas de arquivos, conversas etc.) e de diferentes maneiras (computadores, tablets, smartphones). Além da Internet, bancos, lojas, supermercados e diferentes serviços requerem movimentações financeiras por meio digital, nossos canais de comunicação e de informação estão atrelados a esses recursos tecnológicos. Assim, podemos dizer que as Tecnologias Digitais estão presentes em grande parte dos momentos da vida, em diferentes lugares e ações do ser humano, direta ou indiretamente.

Este avanço tecnológico, bem como as transformações sociais, permitem modificações no ensino, na aprendizagem e na formação com professores/professoras, se fazendo necessária a reflexão sobre esses processos com o uso desse aparato tecnológico, uma vez que a sociedade educacional atual está, em grande parte, introduzida no mundo cibernético. Em especial nesta investigação, destacamos as Tecnologias Digitais (TD) de Realidade Aumentada (RA) que se popularizaram em esfera mundial, entre outros recursos, por meio do jogo Pokémon GO (BBC Brasil, 2016) criado para smartphones no ano de 2016. A RA permite uma composição

1 Essa pesquisa é parte integrante de uma investigação de mestrado da primeira autora. No entanto, possui discussões próprias que se articulam em um foco mais específico. 
do que é mundano com o que é projetado digitalmente, possibilitando a visualização de objetos digitais sem desprender-se da realidade mundana, ou seja, fazendo uma mescla entre, conforme Bulla (2016), o que chamamos de Realidade Mundana e o que é considerada Realidade Virtual em termos de senso comum.

Nesse sentido, as TD de RA também vem trazendo transformaçoes às práticas sociais, em termos de projetos arquitetônicos, construção civil, medicina, entre outras áreas (Fialho, 2018). Devido a isso, consideramos necessário investigar como se dá o trabalho com esse tipo de tecnologia na educação, em especial, na Educação Matemática. Logo, de início, nos propusemos a discutir o papel das TD de RA no processo de constituição do conhecimento matemático, investigando às TD, em específico, as de RA, nesse processo. Para isso, vislumbramos que seria viável que esse entendimento acontecesse, inicialmente, por meio da formação com professores/professoras de matemática, uma vez que esses/essas já possuem uma produção de conhecimento matemático articulada e, assim, poderíamos evidenciar quais possibilidades/diferenças essas TD podem trazer à dimensão matemática desses/dessas professores/ professoras. Além disso, as TD de RA trazem à tona um aspecto espacial proeminente. Elas criam no espaço mundano objetos tridimensionais e, com isso, vislumbrar funções de duas variáveis reais, fugindo de objetos da geometria espacial, um tanto quanto práticos a serem investigados com esse tipo de recurso, também nos pareceu desafiador. Nesse ínterim, assumimos como processo investigativo a análise do processo de constituição de conhecimento matemático de uma professora que desenvolveu atividades-matemáticas-com-TD-de-RA . Esse desenvolvimento foi tomado como a construção de atividades-matemática (elaboração/produção) pela professora e também pela sua colega, assim como, o trabalho com estudantes com uma dessas atividades-matemáticas elaboradas e como o estudo de questões matemáticas relativas a funções de duas varáveis reais com TD de RA (modo de se identificar tópicos matemáticos específicos do estudo com TD de RA).

Assim, com o desenvolvimento de atividadesmatemáticas-com-TD-de-RA ${ }^{2}$ efetuado por essa professora, nos propusemos investigar e relatar nesse artigo indícios de reposta a seguinte pergunta diretriz: como se dá a constituição do conhecimento de uma professora de matenática, sobre pontos de máximo e mínimo de funções de duas variáveis reais, quando essa se insere em um contexto de Realidade Aumentada?

Sendo assim, o presente estudo pretende apresentar a articulação da professora com TD de RA, de forma a compreender, inicialmente, o processo vivenciado por ela e, assim, por meio do referencial teórico que embasa a análise de dados, em consonância com a tipologia de pesquisa e os procedimentos adotados, analisar os dados produzidos.

\section{Pontos Teóricos}

Nas décadas de 1970 e 1980, alguns estudiosos alertavam e questionavam o discurso de que o uso das tecnologias pelos/pelas estudantes em sala de aula faria com que o processo de aprendizagem fosse mecanizado, ou seja, “[...] o aluno iria só apertar teclas e obedecer a orientação dada pela máquina [...]” (Borba \& Penteado, 2003, p.11). Atualmente, os discursos dos estudos mais recentes estão preocupados com outros questionamentos, os quais vão além da defesa ou contrariedade ao uso dessas tecnologias, pois, essa contradição já foi superada no discurso produzido. Assim, a Educação Matemática se transformou em termos de concepção da inserção tecnológica em sala de aula e pesquisas sobre essa transformação, por exemplo, Rosa, Vanini \& Seidel (2011) se referem a como está sendo tratada a constituição do conhecimento matemático com o uso das tecnologias no contexto educacional matemático.

Diante disso, em pesquisas que investigam as potencialidades do trabalho com TD nas aulas de matemática, é importante olhar para a formação de professores/professoras, no que diz respeito ao trabalho com aparatos tecnológicos em sua prática pedagógica. Assim, assumimos que além de inserir as TD em ambientes de ensino e de aprendizagem, o/a docente pode emergir em uma reflexão contínua sobre sua prática.

Nesta pesquisa, então, a formação com professores/ professoras é entendida como um processo de forma/ação (Bicudo, 2003) e abarca a forma/ação do ser em totalidade, a qual não se encerra em processos formais educativos, mas que também está ligada às vivências, às concepções, às práticas desse/dessa professor/professora (Rosa, 2015). Portanto, o ato de formar-se não acontece exatamente em um momento pontual, no qual o sujeito pode armazenar informações e, assim, se estabelece. Os atos de forma/ação buscam as vivências anteriores e vão sendo modificados de acordo com a forma desejada/idealizada de um "ser" professor/professora que é subjetiva, de maneira que esta forma desejada nunca está concluída, mas que é perseguida e almejada como uma forma ideal (Rosa, 2018). Além disso, a forma/ação com TD, do mesmo modo, perfaz um/uma professor/professora que nunca estará formado/formada, ainda com o agravante de estar frente às TD novas a cada dia, vislumbrando um constante processo de forma/ação de um "ser" que está no mundo, é com o mundo, em todos os aspectos, inclusive tecnológicos.

Essa concepção de forma/ação, assumida por nós, traz características específicas do que entende ser a matemática, do

2 Conforme Rosa e Mussato (2015, p.23), atividades-matemáticas-com-TD são atividades que “[...] consideram as Tecnologias Digitais (TD) partícipes do processo cognitivo, ou seja, as TD não são meras auxiliares, não são consideradas ferramentas que agilizam ou fonte motivadora do processo educacional, exclusivamente". Elas condicionam a constituição do conhecimento matemático por meio dessas atividades que, ou não podem ser realizadas/resolvidas sem as TD ou, ao menos, deixam de ser potencializadas pela experiência com as TD, caso não estejam imbricadas no processo.. 
que compreende por constituição do conhecimento matemático e do porquê inserir Tecnologias Digitais (TD) nas aulas de matemática. Essa concepção é denominada "Cyberformação com professores/professoras que ensinam matemática" e se apresenta como um constructo teórico que desvela a prática do/da professor/professora que ensina matemática com Tecnologias Digitais, presencialmente (Dantas, 2016; Bulla \& Rosa, 2017), a distância (Seidel, 2013, Mussato, 2015), de forma mobile (Caldeira, 2016) ou de forma híbrida (Pazuch, 2014), com Realidade Virtual (Pinheiro, 2020) ou com Realidade Aumentada (Schuster, 2020), evidenciando assim uma práxis metodológica embasada epistemologicamente (Vanini, 2015).

A nomenclatura "Cyberformação", então, é composta por duas ideias centrais, nas quais o prefixo "cyber" é visto como indicativo do trabalho com Tecnologias Digitais na própria "forma/ação", a qual é perpassada por várias dimensões (filosófica, sociológica, cultural, colaborativa, política,...), dentre as quais se destacam, no nosso caso, a específica (matemática), a pedagógica e a tecnológica, compreendendo o trabalho com o aparato tecnológico como potencializador da constituição do conhecimento matemático.

A dimensão específica, que trata da matemática, elenca características específicas do assunto matemático em questão com a intenção de que os sujeitos em formação compreendam suas relações com o contexto. Falamos da dimensão específica nos referindo a ela como dimensão matemática e buscando "[...] possibilidades de contextualização da prática docente, aspectos específicos da matemática para que ocorra o ensino e a aprendizagem [...]" (Caldeira, 2016, p.29) e "[...] relações implícitas à própria matemática como linguagem, como ferramenta e/ou campo de estudo" (Rosa, 2015, p.67). De acordo com Seidel (2013), então, a dimensão matemática deve compreender uma matemática que vai sendo constituída pelo ambiente e pela intencionalidade das pessoas que a vivenciam, trata-se de uma matemática aberta, que não está concluída, pronta, mas se constitui no ambiente, proporcionando a constituição do conhecimento matemático, o qual segundo Rosa (2015) se dá pelo próprio fazer matemática.

Nos estudos de Vanini (2015) e Caldeira (2016) fica compreendido que na concepção da Cyberformação, a dimensão matemática não se refere apenas à matemática acadêmica ou escolar, defendida como soberana, mas à uma matemática que faça sentido. Assim, consideramos a matemática emergente no contexto da RA, conforme Schuster (2020), como uma matemática que faça sentido, visto que é no trabalho com RA, é no contexto próprio da RA que o usuário poderá perceber elementos que, muitas vezes, só são possíveis de se perceber ali, e vai alternando sua maneira de participar neste contexto, ou seja, constituindo o conhecimento.

A dimensão pedagógica, por sua vez, refere-se ao processo em que as tecnologias passam a ser partícipes do processo de ensino e são consideradas proeminentes nos processos de educação, transformando-os. Segundo Seidel (2013), a dimensão pedagógica representa as “[...] ações pedagógicas que ocorrem com o mundo cibernético [...]" (Seidel, 2013, p.61), apresentando, então, formas de pensar, refletir e agir sobre algo que só seja possível com o uso da TD, deixando de lado os métodos que se baseiam em sequências do tipo, "faça isso, depois faça isso", como se fossem "receitas", em uma linearidade perceptível. Educar-se matematicamente e educar-se pela matemática (Rosa, 2008, 2018) assumem a ideia de educar-se-matematicamente-com-TD e educarse pela matemática-com-TD, o que vai muito além de uma "receita", uma sequência de "passos", procedimentos ou ações. Significa pensar, refletir, criticar e por meio das TD ir além (Rosa \& Dantas, 2020).

Nessa perspectiva, a dimensão tecnológica está ligada à inserção de TD na perspectiva do ser-com, pensar-com e saber-fazer-com-TD, as quais são atos relativos ao trabalho educacional com TD (Rosa, 2008). Nesse sentido, a concepção de Cyberformação considera as TD como partícipes na constituição do conhecimento, sendo de extrema importância, pois possibilitam conjecturas que sem elas não seriam possíveis ou que não haveria certa abertura a novas questões e perspectivas matemáticas, o que justifica sua inserção por seu caráter potencializador.

Em nosso estudo, destacamos as TD de RA, como um dos possíveis tipos de TD que podem ser trabalhados sob a concepção da Cybeformação, buscando evidenciar seu caratér potencializador da/na constituição de conhecimento matemático. Dizemos isso pois a RA possibilita ao seu usuário grande liberdade para interagir, já que por meio da composição entre objetos virtuais e mundanos, podemos "tocar", circundar e visualizar os objetos em um ambiente $3 \mathrm{D}$, o que pode possibilitar um alto grau de compreensão dele, se comparado a sua visualização apenas por meio de uma projeção 2D.

$\mathrm{O}$ ato de tocar ao estarmos no contexto de RA não se refere ao contato físico/biológico, no sentido do tato. Tocar, no contexto da RA, refere-se a visualizar de maneira sobreposta, de modo que possamos manipular o objeto virtual utilizando o nosso corpo biologicamente encarnado, mas sem a possibilidade de descrever a textura do que tocamos. Também, de modo específico, podemos circundar os objetos virtuais. $\mathrm{O}$ ato de circundar assume o significado literal do verbo que é estar em volta, rodear e absorve ainda, no contexto da RA, a ideia de imersão, no sentido de romper a limitação de observação externa do objeto virtual e entrar no objeto. No entanto, esse entrar não é como quem entra numa piscina, é um entrar pelo qual podemos nos acoplar a ele, unido-nos, compondo-nos com ele (Schuster, 2020).

Entendemos que essa materialidade, criada no contexto da RA, permite uma releitura, interferindo no nosso modo de pensar e agir, já que quando nos "plugamos" às TD, nos transformamos, e assim somos-com-TD e nos identificamos com o ambiente cibernético (Schuster, 2020). Do mesmo modo, ao estarmos com o ambiente de RA, embora estejamos em uma composição, nos sentimos "investindo na aventura", 
já que somos com o mundo cibernético, nos presentificamos "[...] no "ser-com", em "com-junto", ser e [...][mundo cibernético]. Devido a isso, esse ser é múltiplo, pois o [...] [mundo cibernético] também o é. Há uma multiplicidade de seres, os quais variam com o [...][mundo cibernético], enquanto mundo; com os outros pertencentes a esse mundo [...]" (Rosa, 2008, p.79), ou seja, no contexto da RA, especificamente em nossa pesquisa, os holográficos possibilitam uma ação reflexiva da professora, possibilitando a ela ser-com-TD de RA (Schuster, 2020). De acordo com Rosa (2017), o vocábulo "holográficos" é constituído a partir da ideia de gráficos com aspectos de hologramas. Hologramas são imagens tridimensionais obtidas a partir de projeção de luzes sobre figuras. Podendo ser pensados como "fotografias em três dimensões", os hologramas se formam por meio da propriedade ondulatória da luz (Ciência Viva, 2020). Eles diferem-se das fotos tradicionais (2D) pois estas registram somente a intensidade das ondas luminosas, enquanto que os hologramas gravam também as saliências e vales de ondas, criando, com o auxílio de raio laser, as imagens em 3D. Então, sua criação consiste, basicamente, na propagação de luz em somente uma direção (por isso o uso de laser), em um filme hipersensível. A luz do raio é dividida em dois feixes: um ilumina o objeto e reflete sobre o filme e o segundo ilumina diretamente o filme (Martins, 2015).

Figura 1- Esquema para criação de um holograma

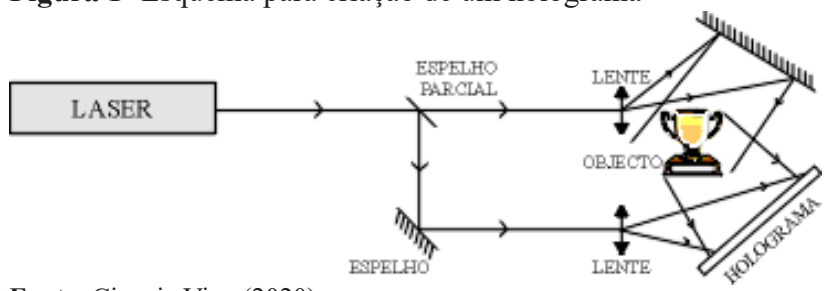

Fonte: Ciencia Viva (2020).

As projeções que estudamos apresentam características que as diferem desses hologramas, por serem criadas não por esquemas com feixe de luzes, mas, por meio de smartphones, extrapolando assim a questão dinâmica e corpórea. Além de apresentarem características de gráficos matemáticos, uma vez que, a origem da palavra gráfico vem " [...] do grego grapho, corresponde a fazer marcas, desenhar, marcar uma pedra, um pedaço de madeira ou uma folha de papel.” (Gráfico, 2020), também representam comportamentos de funções, no nosso caso, de funções de duas variáveis reais. Logo, para nós, desde a origem da palavra gráfico, é possível identificar a necessidade de se fazer entender e/ou explicar com registros visuais as funções matemáticas, no intuito de organizar e contribuir com a compreensão.

Atualmente, na Matemática Acadêmica, existem várias representações gráficas utilizadas nas mais diferentes situações. Dentre essas representações destacamos: gráfico de coluna, histogramas, gráfico de setor, gráfico de linha, etc. Na maioria desses gráficos é possível encontrarmos o eixo cartesiano, pelo qual identificamos uma relação entre as variáveis que estão sendo representadas por ele. Ainda, destacamos a definição de gráfico de funções de uma variável, pois de acordo com Lima (2013), o gráfico de “[...] uma relação $R$ entre os conjuntos $X$ e $Y$ é o subconjunto $G(R)$ do produto cartesiano $^{3} X \times Y$ formado pelos pares $(x, y)$ tais que $x R y$. Assim, $G(R)=\{(x, y) \in X \times Y ; x R y\}$ " (Lima, 2013, p.81), ou seja, quando existir uma relação $R$, entre os conjuntos $X$ e $Y$, o subconjunto dessa relação será o par ordenado $(x, y)$, contido no produto cartesiano $X \times Y$. A figura formada por esses pontos é o que chamamos de "curva" da função. Por exemplo, na Figura 2 temos uma relação dada por $f(x)=x^{2}-4 x+4$.

Figura 2 - Representação gráfica

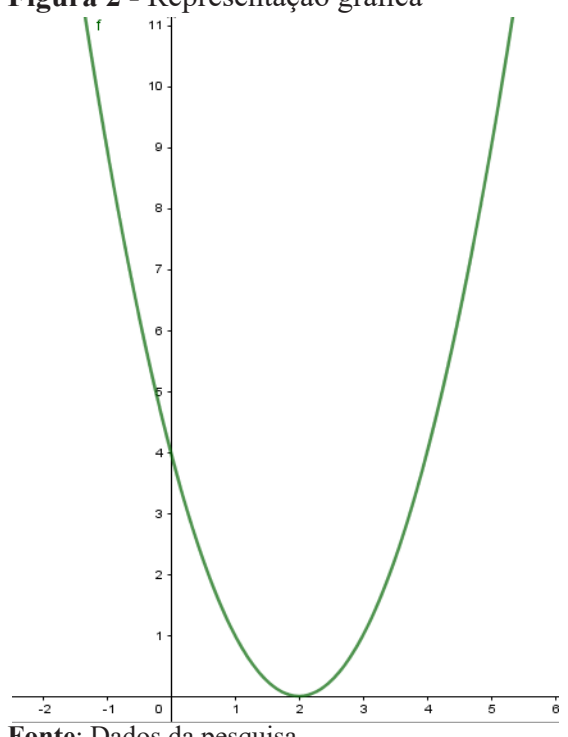

Fonte: Dados da pesquisa.

Existem diferentes softwares para traçar gráficos, entre eles destacamos: GeoGebra 2D e 3D ${ }^{4}$, Minitab $18^{5}$, Graphmatica6, entre outros. Todos os softwares citados projetam gráficos com visualização planificada, ou seja, apresentam uma visualização estática ou com movimentação restrita, pela qual, mesmo que seja possível visualizar o gráfico por diferentes ângulos, essa se dá de maneira planificada, como podemos observar na Figura 3.

3 “O produto cartesiano X x Y de dois conjuntos X e Y é o conjunto X x Y formado por todos os pares ordenados (x,y) cuja primeira coordenada $\mathrm{x}$ pertence a X e cuja segunda coordenada y pertence a Y" (Lima, 2013).

4 GeoGebra é um software gratuito e multiplataforma de matemática dinâmica (disponível para os sistemas Windows, macOS, Chrome OS e Linux, bem como para iOS e Android), considerado, segundo seus criadores, para todos os níveis de ensino. Ele integra geometria, álgebra, planilhas eletrônicas, gráficos, estatísticas e cálculo em um único ambiente.

5 Minitab 18 é um software voltado para o estudo de estatística, que permite ao usuário analisar o comportamento estatístico de determinado banco de dados por meio de representações gráficas.

6 Graphmatica é um software que possibilita a plotagem de gráficos a partir de qualquer tipo de funções e equações inseridas pelo usuário. 
Figura 3 - Diferentes vistas de um tetraedro no GeoGebra 3D
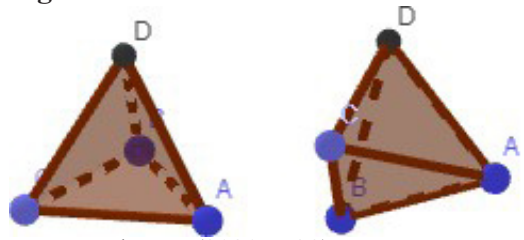

Fonte: Schuster (2020, p.39).

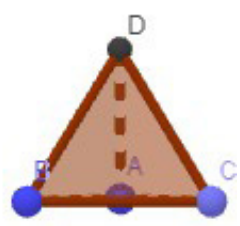

Nesse sentido, não restringimos a nomenclatura da projeção dos objetos virtuais no contexto de RA a gráficos e no caso da Figura 3 a grafos possíveis, pois esse ambiente possibilita uma interação enriquecida com esses objetos. Ou seja, o envolvimento do usuário ao buscar as diferentes vistas de um tetraedro, por exemplo, requer mais do que a manipulação de mouse e teclas de computador. Esse envolvimento se dá na totalidade do corpo-próprio ${ }^{7}$ do usuário naquele momento, já que o seu movimento corpóreo, por exemplo, se torna indispensável para que essas diferentes vistas sejam possíveis (Figura 4).

Figura 4 - Diferentes vistas de um tetraedro no GeoGebra AR

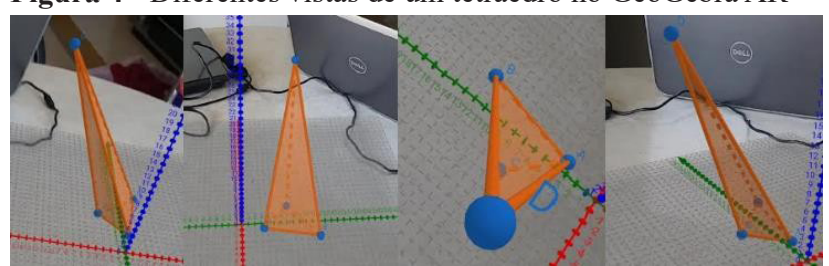

Fonte: Schuster (2020, p.40).

Pressupomos que olhando para as Figuras 3 e 4, o/a leitor/leitora pouco vislumbre os aspectos da discussão acima apresentada, já que em ambas as figuras apresentamos imagens planificadas. Em uma tentativa que se evidencie essas diferenças, convidamos o leitor a aproximar a câmera do seu celular ao $Q R$ Code abaixo e assistir o vídeo que geraram essas vistas da Figura 5.

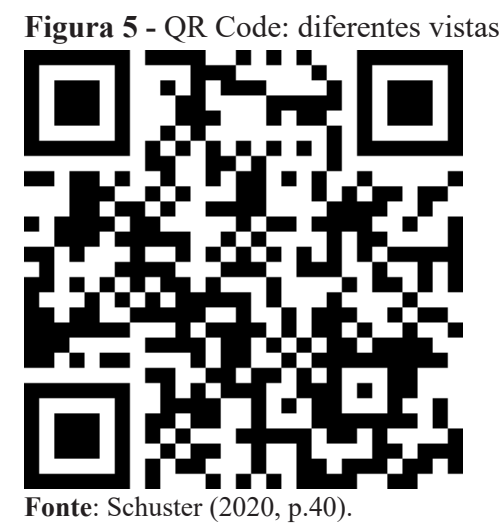

Essa totalidade de ações permite que, no contexto da RA, o usuário conecte-se como holográfico, transformandose, utilizando do seu corpo biologicamente encarnado não mais de forma restrita aos sentidos expressos na realidade mundana, mas passando a ser "[...] alguém que se caracteriza por estar com as tecnologias." (Rosa, 2015, p.70), ou seja, só existe na conexão, só se presentifica com o plugar-se (Bicudo \& Rosa, 2010), pois as TD de RA sustentam essa vivência, no contexto próprio dessa. Segundo Rosa (2015), as TD se tornam mídias envolvidas, ou seja, tornam-se o meio para abrir conexões, no nosso caso, com o contexto da RA. Assim, entendemos que é nessa transformação que o "ser" existe em devir, sendo contextualizado, revelando a concepção de sercom-TD de RA.

Ao explicitarmos “[...] a concepção de pensar-com para uma completa indissociabilidade "ser" [...]" (Rosa, 2008, p. 117) e contexto de RA, entendemos que podemos estar nos tornando cyborgs, ou seja, é “[...] a percepção de quem somos quando estamos conectados à máquina, quando estamos inseridos em um ambiente virtual [contexto de RA], no qual a simbiose entre [corpo-próprio] [...] e computador [no nosso caso, TD de RA] pode acontecer [...]" (Rosa, 2008, p.117). Nesse sentido, o nosso corpo biologicamente encarnado compõe o ambiente mundano, ampliado pelo "virtual" na RA, fomentando a discussão da relação entre o "ser", o "pensar" e o "saber-fazer-com-essa-TD". O corpo é compreendido por nós, em sua totalidade, não sendo fragmentado em corpo biológico/físico e consciência, mas como unidade, assim, “[...] a experiência do corpo próprio [...] revela-nos um modo de existência ambíguo." (Merleau-Ponty, 1999, p. 268). Assumimos, então, o termo corpo-próprio, como modo de dizer desse organismo singular, que não é sem a materialidade do seu corpo, nem do mundo onde se encontra. Ao estarmos no mundo com TD de RA, somos com ele, nos presentificamos em uma faceta própria desse contexto, na qual temos o corpopróprio com TD de RA.

Diante do que foi discutido anteriormente sobre Cyberformação, entendemos, então, que ao estarmos inseridos no contexto de RA, vivenciando-o, experienciando-o, abarcamos a experiência vivida por meio da percepção e essa possibilita o ser-com-TD de RA. Nesse sentido, por meio do ato reflexivo, o ser-com-TD de RA enseja o pensar-com esse contexto, de modo a, estando plugados, nos permitir saberfazer-com-TD de RA, ou seja, habitar a RA intencionalmente em uma forma diferenciada daquela vivida na realidade mundana, exclusivamente (Rosa, 2017).

Essa experiência vivida no contexto da RA, com Tecnologias Digitais, segundo Rosa (2017), também é uma experiência estética, pois não vislumbramos as TD em termos de todo seu engenho analítico, pelo qual sua programação e meios, para que seja possível a execução tecnológica de qualquer coisa, são prioritariamente valorizados, mas porque olhamos para o contexto da RA como algo que fascina, que remete-nos a especulação, por ser um substantivo que "[...] designa qualquer análise, investigação [...] independentede

7 Entendemos corpo-próprio, de acordo com Merleau-Ponty (1999), como uma unidade, não fragmentando o que é fisiológico do que é psicológico, mente e matéria, sendo um organismo singular, que até então não é sem a materialidade do seu corpo, nem do mundo onde se encontra com o outro. 
doutrinas" (Abbagnano, 2007, p.367). Assim, durante essa experiência que nos remete à vivência que permite explorar/ experimentar o belo, em nosso contexto específico da RA, vivenciar as informações que os holográficos evidenciam, mostrando-se a partir do movimento, da cor, da composição com o mundano, e de todas as relações que se façam com esses aspectos é que se constitui, possivelmente, o conhecimento matemático por meio dos atos de ser-com, pensar- com e saber-fazer-com TD de RA.

\section{Variáveis Metodológicas}

Nossa investigação se caracteriza como uma pesquisa qualitativa, pois está mais centrada no processo de compreender "como se dá", do que no resultado final (Bogdan \& Biklen, 1994). Ou seja, estamos focando no entendimento e interpretação de dados e discursos, já que a intenção não foi coletar informações de um número grande de sujeitos visando à quantificação final de uma determinada resposta a uma ou várias perguntas, mas de analisar e compreender os dados produzidos no decorrer do processo por uma única professora, a qual também é pesquisadora desse estudo. A autoanálise seguindo todos os procedimentos éticos e de rigor metodológico se deu após a gravação em áudio e vídeo de todos os momentos de desenvolvimento das atividades, registrando e, posteriormente, transcrevendo as falas e os movimentos desempenhados. A ação de "pensar alto" ocorreu naturalmente, tanto de forma individual quanto na presença de colegas.

Nessa pesquisa, foram utilizados como recursos metodológicos os aplicativos GeoGebra Augmented Reality e 3D Calculator. Além do software o GeoGebra disponibiliza o chamado GeoGebraTube ${ }^{8}$ que é um repositório de vídeos que podem ser compartilhados ou baixados gratuitamente.

Existem dois aplicativos do GeoGebra para trabalharmos com RA. O primeiro a ser lançado foi o GeoGebra Augmented Reality, disponível somente para o sistema operacional iOS. Posterior a esse lançamento, foi disponibilizado também a sua versão para o sistema operacional Android, com poucas alterações em sua interface, intitulado 3D Calculator.

O GeoGebra Augmented Reality e o 3D Calculator possibilitam criar gráficos de matemática em $3 \mathrm{D}$, através da janela de álgebra, na qual podem ser inseridas funções de uma ou duas variáveis reais, além dos objetos tridimensionais já disponíveis (cubo, esfera, pirâmide, cilindro, entre outros). Ambos aplicativos não necessitam de um marcador para centralizar o objeto que está sendo visualizado, o que acaba dando mais liberdade para o usuário no momento de complementar sua visualização com objetos físicos, como por exemplo, uma caneta, e também ao se movimentar em torno dele. O movimento do dispositivo móvel em torno do gráfico fica mais livre, possibilitando além da visualização de todos os lados, a visualização interna do objeto.

\subsection{Pontos Analíticos}

Diante do que foi apresentado na seção Pontos Teóricos, apresentamos dois excertos que emergiram dos dados e que explicitam que a constituição do conhecimento matemático com TD de RA se dá com-holográficos. Ou seja, entre outros excertos que estabeleceram essa característica "comholográficos", apresentamos dois, os quais são definidos como projeções que desvelam momentos em que por meio dos holográficos a professora se pluga, se conecta e se lança às TD de RA, de modo a ser-com-TD de RA, a ser-com-o-holográfico, provocando uma imersão no/com/ao contexto de RA.

\subsection{Ponto máximo de uma função de duas variáveis reais}

No primeiro excerto destacamos um momento em que a professora estava estudando os pontos de máximo e mínimo de funções de duas variáveis reais por meio da RA. A necessidade de entender e identificar esses pontos no holográfico projetado surgiram durante uma atividade realizada em um curso de extensão que a professora participou. A partir dela a professora interessou-se em identificar qual seria o ponto mais alto ou mais baixo dos holográficos, para isso, ela debruçou-se sobre uma função de duas variáveis reais $f(x, y)=9-2 x+4 y-x^{2}-4 y^{2}$ que foi uma das funções utilizadas na atividade.

Analisando o ponto de máximo (VA; GG; 07/03/2020; 00:00:01 - 00:03:51)

[00:00:01] eu tô interessada em localizar, identificar né, os pontos de máximo e mínimo quando existirem, de algumas funções

[00:00:12] eu vou começar, com uma função $f(x, y)=9-2 x$ $+4 \mathrm{y}-\mathrm{x}^{2}-4 \mathrm{y}^{2}$

[00:00:22] primeira coisa que eu vou fazer é colocar o GeoGebra pra trabalhar com Realidade Aumentada e eu vou inserir a função

[00:00:31] então a função como eu já falei é $9-2 x+4 y-x^{2}$ $-4 y^{2}$

[00:00:47] essa folha que tá aparecendo no vídeo (Figura 8) eu tô usando só porque fica melhor, um pouco mais fácil de visualizar em cima da folha branca

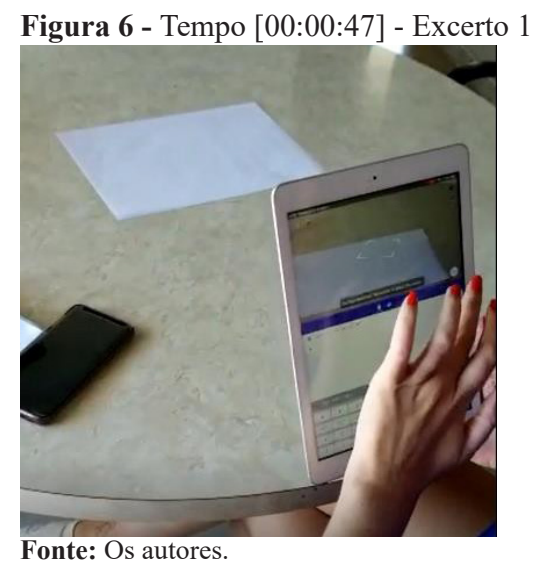

[00:00:56] então é só por isso, né, porque no GeoGebra a gente não precisa de nenhum (...), de nenhum marcador [00:01:06] e aí agora ele vai reconhecer o plano [00:01:12] ou deveria pelo menos 
[00:01:17] tá

[00:01:22] e aí aparece o gráfico lá. Então o que a gente pode ver aqui é que essa função gera um paraboloide ${ }^{9}$ (Figura 7), e aí se eu tô interessada em estudar os pontos de máximo ou de mínimo, eu vou ver se essa curvatura do paraboloide, essa concavidade, vai ficar pra cima ou pra baixo

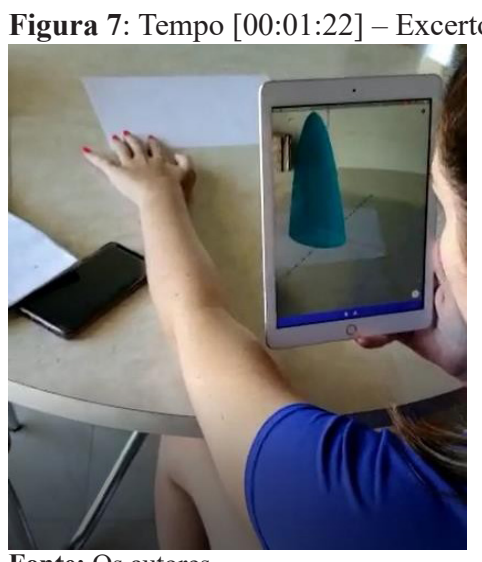

Fonte: Os autores.

[00:01:39] no nosso caso, ele tem concavidade pra baixo, então ele vai ter um ponto máximo, e esse ponto máximo pelo que dá pra identificar aqui, no eixo $\mathrm{z}$ vai ser um ponto [...]

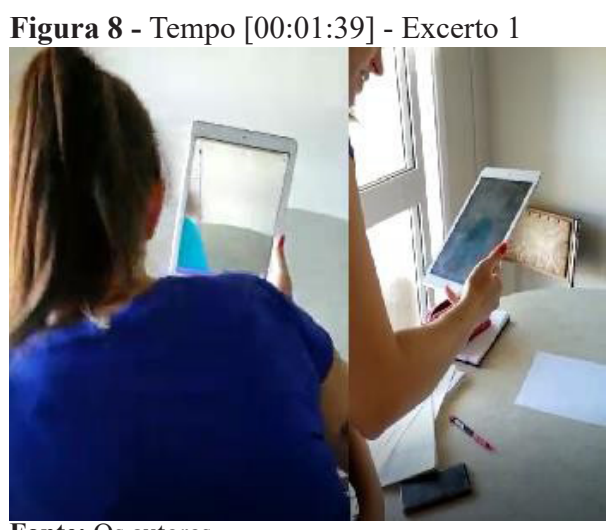

Fonte: Os autores

[00:01:59] que vai, no eixo $\mathrm{z}$ vai corresponder ao ponto 11 (Figura 9), então se a gente colocar (...) a régua ali, até fica um pouco mais fácil de ver, que aqui ó tá bem alinhado com o ponto 11

Figura 9 - Tempo [00:01:59] - Excerto 1

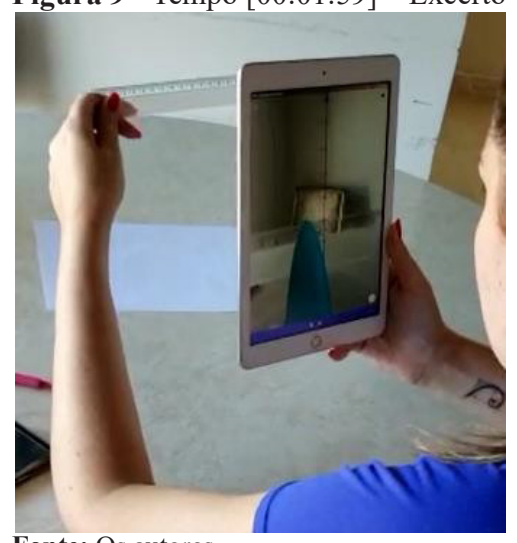

Fonte: Os autores.
[00:02:16] e ai agora, eu vou fazer uma visualização por cima do gráfico (Figura 10) pra conseguir quais são os pontos que vão aparecer lá no eixo $x$ e y

Figura 10 - Tempo [00:01:59] - Excerto 1

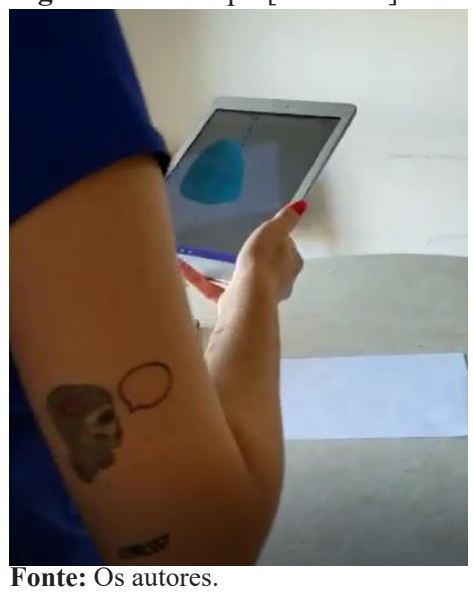

[00:02:28] tá

[00:02:33] então no eixo $\mathrm{x}$ que o que tá sendo representado em vermelho aqui no meu gráfico, eu consigo identificar que o meu ponto através dessas, através dessas parábolas que tão desenhadas aqui em cima do gráfico...

[00:02:51] essa aqui é uma delas, eu consigo ver que ele tá... [00:02:57] no ponto -1 de $\mathrm{x}$, tá então eu tenho o -1 para $\mathrm{o}$, 11 para o y e para o $\mathrm{z} . .$.

[00:03:07] - 1 para o $\mathrm{x}, 11$ para o $\mathrm{z}$ e para o y...

[00:03:18] para o y ele vai tá bem no meio entre 0 e (...)

[00:03:26] e o 1

[00:03:29] então ele vai tá no 0,5

[00:03:38] tá bem no meio entre o 1 e 0

[00:03:42] então o ponto de máximo da função vai ser $(-1$, $0,5,11)$

[00:03:51] esse é o ponto de máximo e a gente pode afirmar isso porque se a gente traçar (...) considerar esse ponto crítico (Figura 11) que é o ponto que eu falei agora, e passar pelo paraboloide, várias parábolas que sobem aqui nele, passando por esse ponto crítico (a professora utiliza esse conceito matemático no contexto de RA de acordo com os conhecimentos que possui previamente sobre ele), todas as parábolas vão ter esse ponto como sendo o ponto de máximo, então por isso que a gente pode afirmar que ele é o ponto de máximo desse paraboloide.

Figura 11 - Tempo [00:03:51] - Excerto 1

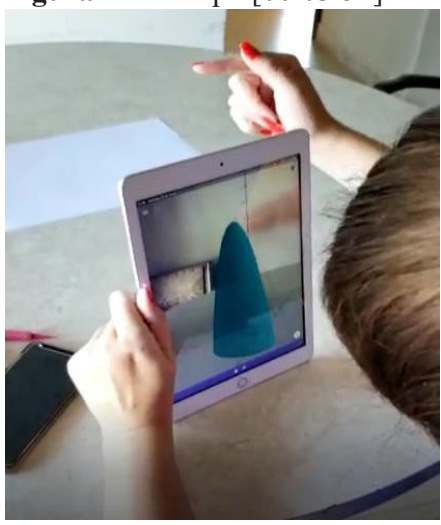

Fonte: Os autores. 
Neste excerto, destacamos a maneira encontrada pela professora para encontrar o ponto de máximo da função estudada, utilizando somente o holográfico, sem recorrer à resolução algébrica, a partir do momento [00:01:22], no qual o holográfico da função está projetado sob a mesa na qual a professora está trabalhando. Nesse momento, a professora identifica que o holográfico ali projetado representa um paraboloide recorrendo aos seus conhecimentos prévios e a lembrança de alguns gráficos de funções de duas variáveis reais já construídos por ela durante sua vida acadêmica.

Após identificar que o holográfico ali projetado refere-se a um paraboloide, a professora anda em volta do holográfico (Figura 8) para que possa ter diferentes visualizações e certificar-se que "[00:01:39] [...] ele tem concavidade para baixo, então [...] vai ter um ponto máximo.”. Entendemos esse andar em volta do gráfico como uma especulação, como algo que fascina ao possibilitar descobrir fatos sobre a função que está sendo estudada de uma maneira diferente da algébrica. Para nós, esse "caminhar em torno de" possibilita a professora uma ação reflexiva, já que transforma a sua participação nesse contexto, no qual ela passa a ser "[...] alguém que se caracteriza por estar com as tecnologias." (Rosa, 2015, p.70), interferindo sua maneira de pensar e agir, intencionalmente habitando o contexto criado pela RA de modo reflexivo e percebendo que ao "[00:02:16] [...] fazer uma visualização por cima do gráfico [...]", abrem-se possibilidades de ações reflexivas, em que nos damos conta de nós mesmos, de nossas ações e do que dizem, podendo concluir assim "[00:02:16][...]quais são os pontos que vão aparecer[...]no eixo x e y.”. Entendemos que, de acordo com Rosa (2008), quando a professora se percebe, situa-se no contexto criado pela RA, já que há uma ação reflexiva com esse processo, ela está envolta pela ação de ser-com-TD de RA.

Ao estar no contexto da RA, a professora identifica elementos utilizados frequentemente no contexto da Matemática Acadêmica ou escolar, mesmo que na RA possam não se apresentar da mesma forma. Verificamos isso quando percebe que o"[00:02:33][...] eixo x [...] está sendo representado em vermelho [...]", e que ele pode estar tanto na horizontal ou na vertical nesse contexto, dependendo da maneira e da perspectiva de visualização que ela faz do holográfico, enquanto que em um gráfico estático, normalmente essa coordenada está sempre na mesma posição em relação ao leitor, na horizontal. Entendemos que ao girar um livro com a imagem de um gráfico, por exemplo, poderíamos também ter o eixo das abscissas representado em outra direção, porém o restante do contexto, textos e imagens estariam também invertidos, dificultando ou impossibilitando sua compreensão. Além disso, o holográfico se constitui com elementos que não costumamos elencar no gráfico estático, um exemplo disso é a projeção das unidades de medidas utilizadas em cada eixo ordenado, como pode ser visto na Figura 12. Essa projeção é representada na cor preta, e indicada pela flecha.

Figura 12 - Projeção das unidades de medida dos eixos no holográfico

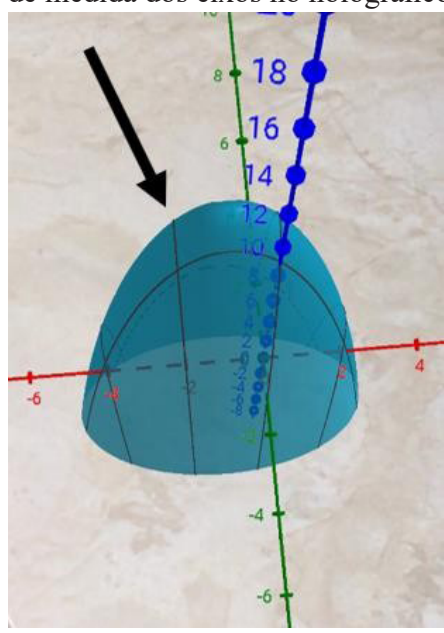

Fonte: Os autores.

A projeção das unidades de medidas de cada eixo no holográfico foi bastante importante para a resolução da atividade inicial, ao afirmar que "[00:02:33] [...] eu consigo identificar o meu ponto através dessas, através dessas parábolas que tão desenhadas em cima do gráfico... ". Ou seja, a constituição do conhecimento aqui se apresentou de maneira indissociável do contexto criado pela RA, visto que foram características próprias desse contexto que possibilitaram a resolução do problema inicial, sendo uma ação cognitiva que levou a professora a estabelecer sentidos com o mundo e com as possibilidades de situar-se nesse espaço específico da RA, de ser-com-TD de RA (Rosa, 2008).

Após identificar o ponto de máximo da função, que era “[00:03:42] [...] $(-1,0.5,11)$. , utilizando como referência elementos próprios do holográfico, a professora preocupase em garantir que esse ponto seja máximo em relação a todas as possíveis visualizações da função. Para isso, além de novamente "andar em volta do holográfico", a professora verifica a hipótese de que se“[00:03:51][...]passar pelo paraboloide várias parábolas que sobem [...] nele, passando por esse ponto crítico, todas as parábolas vão ter esse ponto como sendo ponto de máximo, então por isso que a gente pode afirmar que ele é o ponto máximo [...]". Ao fazer isso, ela visualiza diferentes parábolas acopladas ao paraboloide, que tenham o ponto crítico pertencente a sua representação. Com isso, percebe que todas elas terão o ponto crítico como sendo o seu ponto de máximo, ou seja, terão concavidade para baixo. Para nós, nesse momento, a professora não segue as formas expressas comumente nos livros didáticos ou sintetizadas em aulas de matemática, embora utilize aspectos já existentes, o fazer em termos matemáticos se mostra diferente, ou seja, evidencia a constituição do conhecimento matemático. Nesse sentido, ao realizar esses testes com parábolas acopladas ao parabolóide a professora visualizou essas parábolas de duas maneiras: a primeira delas tendo como referência o eixo $\mathrm{x}$ 
e a segunda tendo como referência o eixo y. Então, testou as parábolas do tipo $f(x)=a x^{2}+b x+c$ e do tipo $f(y)=$ $d y^{2}+e y+\mathrm{g}$, encontrando em ambas "[00:03:51] [...] todas às parábolas vão ter esse ponto como sendo o ponto de máximo [...]", ou seja, terão a concavidade para baixo, isso significa que ambos os coeficientes $a$ e $d$ são negativos, o que, associado à visualização do holográfico, permitiu que a professora afirmasse que o ponto crítico “[00:03:51] [...] é o ponto máximo desse paraboloide.”.

Embora em sua atividade com o holográfico a professora não tenha utilizado o Teste da Segunda Derivada (Figura 13) para identificar os valores de máximo e mínimo, é possível encontrarmos indícios em sua resolução no contexto de RA que indiquem uma semelhança entre o que é feito com o holográfico e a resolução algébrica do teorema. Dizemos isso, pois de maneira genérica, podemos afirmar que parábolas com coeficientes que acompanham o termo ao quadrado (no caso, $a$ e $d$ ) são negativos e, devido a isso, conforme Lima (2013, p.122) "Se a parábola é o gráfico da função $f(x)=a x^{2}+b x$ $+c$, sua tangente (...) tem inclinação igual a $2 a x_{0}+b$.”, terão também retas tangentes com coeficientes angulares negativos. Com isso teríamos as retas $f^{\prime}(x)=-a x+b$ e $f^{\prime}(y)=b-d y+e$. Se quisermos também saber a taxa de variação da própria variação destas funções teríamos $f$ " $(x)=-a$ e $f^{\prime \prime}(y)=-d$, ou seja, a derivada segunda também seria negativa.

Figura 13 - Teste da Segunda Derivada

3 Teste da Segunda Derivada Suponha que as segundas derivadas parciais de $f$ sejam contínuas em uma bola aberta com centro em $(a, b)$, e suponha que $f_{x}(a, b)=0$ e $f_{y}(a$, $b)=0$ [ou seja, $(a, b)$ é um ponto crítico de $f]$. Seja

$$
D=D(a, b)=f_{x x}(a, b) f_{y y}(a, b)-\left[f_{x y}(a, b)\right]^{2}
$$

(a) Se $D>0$ e $f_{x r}(a, b)>0$, então $f(a, b)$ é um mínimo local.

(b) Se $D>0$ e $f_{\text {cr }}(a, b)<0$, então $f(a, b)$ é um máximo local.

(c) Se $D<0$, então $f(a, b)$ não é mínimo local nem máximo local.

Fonte: Stewart (2013, p. 851).

De acordo com o teorema, para que tenhamos um ponto de máximo precisamos que $D>0$ e $f_{x x}(a, b)<0$. Assim, temos que $f_{x x}(a, b) \cdot f_{y y}(a, b)-$ $\left[f_{x y}(a, b)\right]>0$, como o segundo termo sempre será negativo, já que todo número real elevado ao quadrado resulta em um número real positivo, necessariamente o primeiro termo deve ser positivo, e isso só irá ocorrer quando $f_{x x}(a, b)$ e $f_{y y}(a, b)$ forem simultaneamente ou maiores ou menores que zero, e maior que o segundo termo. Entendemos, então, que ao analisarmos as possíveis parábolas acopladas ao parabolóide, considerando como domínio o eixo $\mathrm{x}$ e posteriormente o eixo $y$, ao pensarmos na sua concavidade e, por consequência, em sua reta tangente, que nos direciona à derivada segunda, a professora faz, mesmo que de maneira mais direta, essa relação entre as diferentes parábolas que podem ser acopladas ao parabolóide.
3 Pontos de máximo e mínimo de uma função de duas variáveis reais: não existem?

Após realizar a atividade apresentada no excerto anterior, a professora deu continuidade, isto é, sentiu-se instigada a dar continuidade aos estudos de ponto de máximoedemínimo.Para tanto escolheu a função de duas variáveis reais $f(x, y)=x^{2}-y^{2}$ + 8. É máximo ou mínimo? (VA; GG; 07/03/2020; 00:00:09 $-00: 03: 15)$

[00:00:09] já to conseguindo visualizar ela (referindo-se ao gráfico da função, conforme figura 14), então nesse gráfico da função $\mathrm{f}(\mathrm{x}, \mathrm{y})=\mathrm{x}^{2}-\mathrm{y}^{2}+8$, vou identificar se ele tem um ponto de máximo ou de mínimo e aí identificar qual é

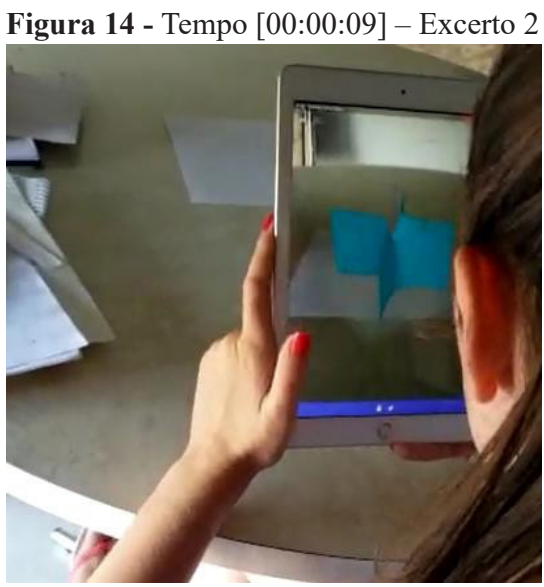

Fonte: Os autores.

[00:00:22] já dá pra ver né, pelo formato do gráfico que ele não vai ter um ponto de máximo ou de mínimo, mas que ele tem esse ponto crítico (conforme explicitado anteriormente, a professora refere-se a esse conceito matemático no contexto de RA de acordo com os seus conhecimentos prévios sobre ele) aqui que vai ser no ponto zero (Figura 15). No ponto zero, zero e oito, então esse é um ponto crítico do gráfico

Figura 15 - Tempo [00:00:22] - Excerto 2

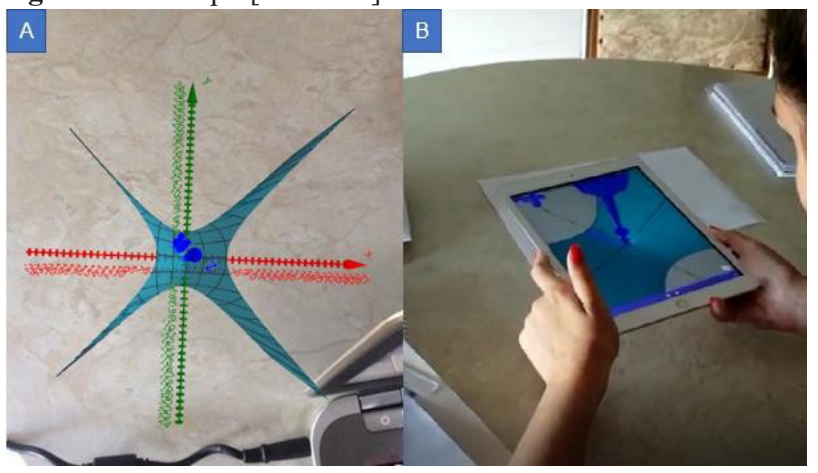

Fonte: Os autores.

[00:00:55] se a gente olhar em relação ao eixo $\mathrm{x}$, em relação ao eixo x, a gente vai ter, se pegar só o eixo x (Figura 16), a gente vai ter uma concavidade pra cima e aí nesse ponto vai ser um ponto de mínimo. Então, se a gente fosse traçar né, como eu tinha pensado, de traçar uma parábola, a gente ia ter uma parábola de concavidade pra cima e um ponto de mínimo local ${ }^{11}$ (assim, como ponto crítico a professora utiliza esse conceito de acordo com seus conhecimentos prévios)

7 Se $f(x, y)>=f(a, b)$ quando (x,y) está próximo de (a,b), então f tem um mínimo local.” (Stewart, 2013, p.850). 
Figura 16 - Tempo [00:00:55] - Excerto 2

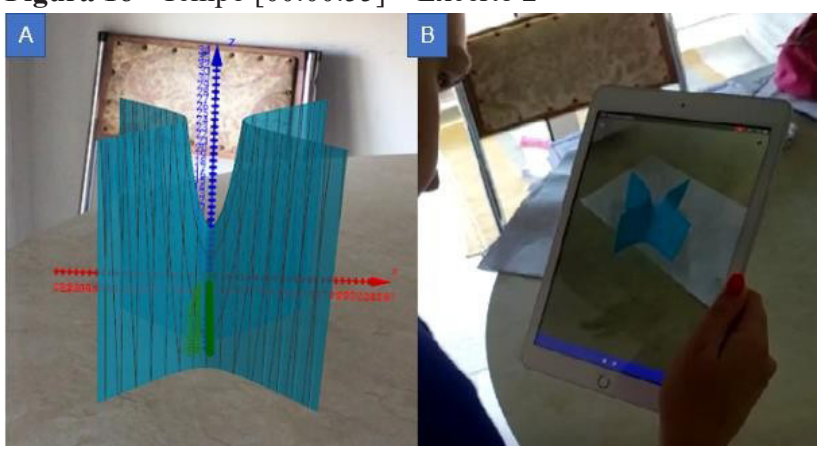

Fonte: Os autores.

[00:01:47] mas, se a gente for olhar isso em relação a y (Figura 17), a gente vai ter um ponto, vai ter ao contrário, vai ter uma parábola com concavidade pra baixo e aí esse ponto $(0,0,8)$ vai ser um ponto de máximo local ${ }^{12}$

Figura 17 - Tempo [00:01:47] - Excerto 2

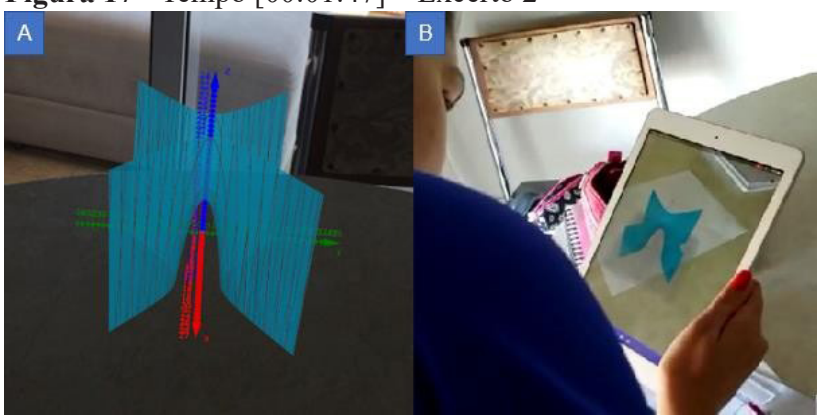

Fonte: Os autores.

[00:02:15] acho que desse lado aqui dá pra ver melhor, quase as duas coisas acontecendo ao mesmo tempo, onde pra lá é um ponto de máximo e aqui é um ponto de mínimo

[00:02:35] tá, então isso é o que a gente chama de ponto de sela, mas eu tô pensando porque que a gente pode dizer que é um ponto de sela, considerando aquele teorema lá (referindose ao teorema da regra da cadeia) que diz que pra ser um ponto de sela o determinante tem que ser menor que zero [00:03:15] ah eu acho que vai ser menor do que zero porque eu vou ter, se eu fosse traçar uma reta tangente ou um plano tangente nesse caso, a gente ia ter um plano decrescente e um plano crescente, então com coeficiente, um coeficiente positivo e outro com coeficiente negativo e aí na hora de fazer as multiplicações lá das derivadas né, da derivada primeira a gente teria uma multiplicação de um número positivo por um número negativo e aí a resposta vai ser um número negativo, logo menor do que zero. Acho que por isso.

Esta projeção demonstra também a determinação de ponto crítico de uma função de duas variáveis reais utilizando o contexto da RA, e as interações possíveis nele. No entanto, nesse caso o ponto crítico não pode ser caracterizado como um ponto de mínimo ou de máximo já que essa determinação muda, pois "[00:00:55]se a gente olhar em relação ao eixo $\mathrm{x}$ [...] a gente vai ter uma concavidade pra cima e aí nesse ponto vai ser um ponto de mínimo [...]”, “[00:01:47] mas, se a gente for olhar [...] em relação a y, [...] vai ter uma parábola com concavidade para baixo e aí esse ponto [...] vai ser um ponto de máximo [...]". Como a determinação desse ponto depende do ângulo de visualização, ou seja, do eixo tomado como referencial, a professora conclui que "[00:02:35][...] então isso é o que a gente chama de ponto de sela $[\ldots]$ ".

A aprendizagem também tem esse caráter relacional entre o contexto de RA e a professora. Consideramos importante ressaltar que esse caráter relacional não se dá como uma relação de associação entre a professora e a tecnologia, mas como a ação intencional da professora ao manifestar-se nesse mundo, vivenciando-o intencionalmente (Rosa, 2017).

Ao dizer que "[00:00:55] [...] se a gente fosse traçar né, como eu tinha pensando, de traçar uma parábola [...]", a professora faz referência à maneira já utilizada por ela anteriormente para pensar em parábolas acopladas ao parabolóide, de maneira que possa generalizar uma conclusão. De acordo com Caldeira (2016), entendemos que ao fazer isso a professora não está apenas utilizando as TD de RA para facilitar ou acelerar um determinado processo, mas utilizandose de algo que vislumbrou com ela que resolve a atividade naquele contexto. Para nós também, é possível identificar que a professora se lança à atividade sem que seja preciso "dominar" essa tecnologia, aprendendo com ela, estando em um movimento contínuo de forma/ação (Seidel, 2013).

Identificamos que o contexto da RA possibilitou também a professora pensar em novas questões e conjecturas, trazendo o questionamento ao Teste da Segunda Derivada, ao relacionar com o que era evidenciado pelo holográfico. Essa dialética entre a professora e o contexto de RA, evidencia que ela não é uma receptora passiva de conhecimento que está no mundo, sendo por meio do seu engajamento integral (corpo, mente, sensibilidades e contexto) com as situações que possibilitam concluir, por exemplo, “[00:03:15] [...] que vai ser menor do que zero porque eu vou ter [...] um plano decrescente e um plano crescente, então [...] um coeficiente positivo e outro com coeficiente negativo e [...] teria a multiplicação de um número positivo por um número negativo e ai a resposta $[\ldots]$ vai ser um número negativo, logo menor que zero $[\ldots]$ ”. Assim, justificando o seu caráter potencializador da inserção das TD de RA, já que as TD foram partícipes nessa conclusão, feita pela professora (Rosa, 2008).

\section{Considerações Finais}

Nesta pesquisa, investigamos como se dá a constituição do conhecimento sobre pontos de máximo e mínimo, de funções de duas variáveis reais, com uma professora ao se inserir no contexto da Realidade Aumentada. A partir da análise dos excertos, foi possível perceber que a constituição do conhecimento se dá pelo envolvimento na totalidade que o contexto da RA possibilita. Esse envolvimento em totalidade é observado por nós, evidenciando no movimento corpóreo realizado pela professora para que pudesse ter diferentes visualizações do holográfico, fazendo com que ela se conectasse com-o-holográfico, transformando-se, 
caracterizando-se ao estar com essa TD, passando a sercom-TD de RA. Sendo o ato de pensar indissociável do ser, concluímos também que a professora passa a pensar-com-TD de RA e saber-fazer-com-TD de RA.

Logo, entendemos que esse envolvimento em sua totalidade é, por si só, algo que modifica a constituição do conhecimento, pois essas diferentes visualizações permitidas pelo ato de mover-se em torno do gráfico se dão de maneira diferente do que manipular um gráfico planificado. Esse processo sugere que a forma/ação com TD de RA, a qual, em parte foi analisada em momentos individuais da professora, não se dá sem as relações e interrelações consigo mesma, com os outros e com mundo. A professora em Cyberformação pois lança-se ao trabalho com o Geogebra AR sem dominá-lo, sem acreditar que esse seria motivador, auxiliar ou um recurso da moda, permite-se ser-com, pensar-com e saber-fazer-com-TD de RA de forma que esse tipo de TD apresenta-se partícipe do seu processo de constituição do conhecimento, elencando aspectos não algébricos e outros que trazem à tona seu movimento corpóreo como ação diferencial e proeminente na compreensão de máximos e mínimos.

Assumimos que a compreensão de como se dá a constituição do conhecimento sobre pontos de máximo e mínimo, de funções de duas variáveis reais, com uma professora de matemática ao se inserir no contexto da Realidade Aumentada contribui para identificarmos como essa constituição também pode ocorrer com os estudantes que vislumbrem esse tópico matemático, assim como, contribui para que professores de matemática que vierem a trabalhar com esse tópico, por meio de TD de RA, venham a planejar suas atividades aproveitando esses resultados e explorando o movimento corpóreo dos seus estudantes por meio da experiência/vivência com os holográficos projetados.

\section{Referências}

Abbagnano, N. (2007). Dicionário de filosofia. São Paulo: Martins Fontes.

BBC Brasil (2016). O que é o Pokémon Go e por que está causando tanto furor no mundo dos games? Disponível: < http://www.bbc.com/portuguese/geral-36802725>. Acesso em: 28 set. 2020 .

Bicudo, M. A. V. (2003). A formação do professor: um olhar fenomenológico. In: M. A. V. Bicudo (Org.). Formação de Professores. Bauru: EDUSC, p.7-46.

Bicudo, M. A. V. \& Rosa, M. (2010). Realidade e cibermundo: horizontes filosóficos e educacionais antevistos. Canoas: ULBRA.

Bogdan, R. C.\& Biklen, S. K. (1994). Investigação qualitativa em educação. Porto: Porto Editora.

Borba, M. C. \& Penteado, M. G. (2003). Informática e Educação Matemática. B. Horizonte: Autêntica.

Bulla, F. D. (2016). Modelagem Matemática na Perspectiva da Realidade Aumentada: possibilidades à formação de professores. Porto Alegre: Universidade Federal do Rio Grande doSul.
Bulla, F. D. \& Rosa, M. (2017). O Design de TarefasMatemáticas-com-Realidade Aumentada: uma autorreflexão sobre o processo. Acta Scientiae, 19 (2), 296-319.

Caldeira, J. P. S. (2016). Conexões Matemáticas entre Professores em Cyberformação Mobile. Dissertação (Mestrado em Ensino de Ciências e Matemática). Universidade Luterana do Brasil - ULBRA, Canoas.

Ciência Viva. Hologramas. Disponível em: <http://www. cienciaviva.pt/projectos/pulsar/hologramas.asp $>$. Acesso em: 16 maio 2020.

Dantas, D. M. (2016). A Criatividade Tecnológica na Construção de Atividades com Professores de Matemática em Cyberformação. Dissertação (Mestrado em Ensino de Ciências e Matemática) - Programa de Pós-Graduação em Ensino de Ciências e Matemática, Universidade Luterana do Brasil, Canoas.

Fialho, A. B. (2018). Realidade virtual e aumentada: tecnologias para aplicações profissionais. São Paula: Érica.

Gráfico. (2020). In: Dicionário Etimológico. Disponível em: $<$ https://www.dicionarioetimologico.com.br/grafico/>. Acesso em: 12 maio 2020

Lima, E. L. (2013). Números e Funções Reais. Rio de Janeiro: SBM.

Martins, L. (2015). Conheça a origem dos hologramas e as aplicações da tecnologia hoje. Techtudo. Disponível em: $<$ https://www.techtudo.com.br/noticias/noticia/2015/02/ conheca-origem-dos-hologramas-e-aplicacoes-datecnologia-hoje.html>. Acesso em: 20 dez. 2020.

Merleau-Ponty, M. Fenomenologia da percepção. São Paulo: Martins Fontes, 1999.

Mussato, S. (2015). Cyberformação com Professores de Matemática a Distância: horizontes que emergem de diferentes contextos culturais. Tese (Doutorado em Ensino de Ciências e Matemática) - Programa de Pós-Graduação em Ensino de Ciências e Matemática, Universidade Luterana do Brasil, Canoas.

Pazuch, V. (2014). Cyberformação semipresencial: a relação com o saber de professores que ensinam matemática. Tese (Doutorado em Ensino de Ciências e Matemática) - Programa de Pós-Graduação em Ensino de Ciências e Matemática, Universidade Luterana do Brasil, Canoas.

Pinheiro, R. P. (2020). Professores/professoras que ensinam matemática conectados/conectadas à realidade virtual: como se mostra a cyberfomação? Dissertação (Ensino de Matemática), Programa de Pós-Graduação em Ensino de Matemática, Instituto de Matemática, Universidade Federal do Rio Grande do Sul, Porto Alegre.

Rosa, M. (2008). A Construção de Identidades Online por meio do Role Playing Game: relações com o ensino e aprendizagem de matemática em um curso à distância. Tese (Doutorado em Educação Matemática) - Instituto de Geociências e Ciências Exatas, Universidade Estadual Paulista, Rio Claro.

Rosa, M. (2015). Cyberformação com Professores de Matemática: interconexões com experiências estéticas na cultura digital. In: M. Rosa, M. Bairral \& R. B. Amaral, Educação Matemática, Tecnologias Digitais e Educação a Distância: pesquisas contemporâneas. Natal (RN): Editora da Física.

Rosa, M. (2017). Insubordinação Criativa e a Cyberformação com professores de Matemática: desvelando experiências estéticas por meio de tecnologias de Realidade Aumentada. Rev Ensino Ciênc. Matem., 8(4),157-173. doi: https://doi.org/10.26843/ rencima.v8i4.1500 
Rosa, M. (2018). Tessituras teórico-metodológicas em uma perspectiva investigativa na Educação Matemática: da construção da concepção de Cyberformação com professores de matemática a futuros horizontes. In: A. M. P. de Oliveira \& M. I. R. Ortigão (Org.). Abordagens teóricas e metodológicas nas pesquisas em educação matemática. 1ed.Brasília: SBEM, pp. 255-281.

Rosa, M. \& Bicudo, M. A.V. (2019). Focando a constituição do conhecimento matemático que se dá no trabalho pedagógico que desenvolve atividades com tecnologias digitais. In.: Paulo, R. M. Paulo, I. C. Firme, C. C, Batista. Ser professor com tecnologias: sentidos e significados. São Paulo: UNESP.

Rosa, M., \& Dantas, D. M. (2020). Criatividade tecnológica: um estudo sobre a construção de atividadesmatemáticas-com-tecnologias-digitais por professores/ as em cyberformação. Zetetike, 28, e020030. https://doi. org/10.20396/zet.v28i0.8654423

Rosa, M. \& Mussato, S. (2015). Atividade-Matemática-comTecnologias-Digitais-e-Contetxos-Culturais:investigando o design como processo de Cyberformação com professores de matemática. JIEEM - Jornal Int. Estud. Educ. Matem., 8 (4), $23-42$.

Rosa, M. \& Vanini, L. \& Seidel, D. J. (2011). Produção do conhecimento matemático online: a resolução de um problema com o Ciberespaço. Boletim GEPEM, 58 (1), 89113.

Schuster, P. E. S. (2020). Uma professora em cyberformação com tecnologias digitais de realidade aumentada: como se dá a constituição do conhecimento matemático? Dissertação (Ensino de Matemática), Programa de Pós-Graduação em Ensino de Matemática, Instituto de Matemática, Universidade Federal do Rio Grande do Sul, Porto Alegre.

Seidel, D. J. (2013) O professor de matemática online percebendo-se em Cyberformação. Tese (Doutorado em Ensino de Ciências e Matemática), Universidade Luterana do Brasil - ULBRA, Canoas.

Stewart, J. (2013). Cálculo. v. 2. São Paulo: Cengage Learning.

Vanini, L. (2015). A construção da concepção da cyberformação por professores e tutores de matemática online na formação continuada e na sua prática: uma análise bourdieana. Tese (Doutorado em Ensino de Ciências e Matemática), Universidade Luterana do Brasil, Canoas.

Vanini, L., Rosa, M., Justo, J. C. R. \& Pazuch, V. (2013). Cyberformação de Professores de Matemática: olhares para a dimensão tecnológica. Acta Scientiae15 (1), 153-171. 